\title{
Morphology of caterpillars and pupae of European Maculinea species (Lepidoptera: Lycaenidae) with an identification table
}

\author{
Ewa B. Śliwińska, Piotr Nowicki, David R. Nash, Magdalena Witek, Josef Settele \\ \& Michal Woyciechowski
}

Śliwińska, E. B., Nowicki, P., Nash, D. R., Witek, M., Settele, J. \& Woyciechowski, M. 2006: Morphology of caterpillars and pupae of European $\mathrm{Macu}$ linea species (Lepidoptera: Lycaenidae) with an identification table. - Entomol. Fennica 17: 351-358.

Of the four recognized Maculinea species that occur in Europe, three (M. teleius, $M$. nausithous, and $M$. alcon) are found on damp meadows, and may co-occur; sometimes their larval instars even occupy the same host ant nest. It is, therefore, important to be able to distinguish between the caterpillars of these species for effective conservation. We present the morphology of the larvae and pupae of these three species, and a simple key to their identification. Inter-specific differences among larvae and pupae, and within-species differences among larval instars, are underlined in order to enable their proper identification. The length, colour and distribution of bristles are considered the best features for species and instar identification. The morphology of the described species is compared with that of the other European species, M. arion.

E. B. Śliwińska, P. Nowicki, M. Witek and M. Woyciechowski, Instistute of Environmental Sciences, Jagiellonian University, Gronostajowa Street 7, 30-387 Krakow, Poland; E-mail: ewa sliwinska@yahoo.ca

D. R. Nash, Centre for Social Evolution and Symbiosis, Department of Population Biology, Institute of Biology, University of Copenhagen, Universitetparken 15,DK-2100, Copenhagen $\breve{R}$, Denmark; Email: drnash@bi.ku.dk

$J$. Settele, Centre for Environmental Research Leipzig-Halle, Department of Community Ecology, Theodor-Lieser-Strasse 4, 06120 Halle/Saale, Germany; Email: settele@halle.ufz.de

Received 12 August 2005, accepted 24 November 2005

\section{Introduction}

Maculinea species are parasitic myrmecophilous butterflies in the family Lycaenidae. In Europe, the genus Maculinea includes four species, all of which are considered vulnerable or threatened. $M$. arion Linnaeus, $M$. alcon Denis \& Schiffermüller and its ecological race $M$. rebeli Hirschke, $M$. teleius Bergsträsser and $M$. nausithous Berg- strässer. The distinction between $M$. alcon and $M$. rebeli has been suggested only recently and it is supported by ecological (Thomas et al. 1989, Munguira 1989, Munguira \& Martin 1993) but not genetic (Als et al. 2004, Bereczki et al. 2005) differences.

All Maculinea species are characterized by an unusual life cycle. The adults lay eggs on specific foodplants. The caterpillars feed on or in the 
flowerheads of these plants for the first three larval instars. The fourth instar caterpillars leave the foodplant immediately after moulting, and drop to the ground, after which they are adopted by Myrmica ants. The larvae remain as fourth instars within the ant nest for approx. 10 or 22 months, during which time they increase their body mass almost one hundred times without moulting (Thomas 1984, Elmes et al. 1991). At that period they feed on ant grubs, trophic eggs and ant regurgitations. Pupation also takes place within the ant nest.

The ranges and habitats of three European Maculinea species, viz. M. teleius, $M$. nausithous and $M$. alcon, show considerable overlap (Wynhoff 1998) and they often occur sympatrically on wet lowland meadows. Females of $M$. teleius and $M$. nausithous oviposit on the same food plant, Sanguisorba officinalis L., although there are differences in the position and phenological stage of flowers used: $M$. teleius tends to oviposit on young flowerheads of $S$. officinalis with closed petals, located at medium plant height, whereas $M$. nausithous usually selects relatively old flower buds at the top of plants (Figurny \& Woyciechowski 1998, Wynhoff 2001). M. alcon oviposits on Gentiana pneumonanthe L., although the species is also known to use other food plants of the genus Gentiana in other localities (Thomas 1984, Jutzeler 1988, Wynhoff 2001). The pattern of caterpillar co-occurrence in ant nests is even more complex, as in some populations two Maculinea species may use the same host ant and can be found together in a single nest (Sielezniew \& Stankiewicz 2001, Stankiewicz \& Sielezniew 2002).

As a consequence, it is not possible to distinguish between the caterpillars and pupae of these three co-occurring species only based on foodplant or host ant species used. On the other hand, correct species identification within this specialized genus is necessary for accurate studies of Maculinea ecology (e.g. host ant specificity, competition between co-occurring $\mathrm{Macu}$ linea species, population genetic research) and for conservation. The aim of this paper is to present simple morphological features that can be used to distinguish the species and larval instars of juveniles of $M$. nausithous, $M$. teleius and $M$. alcon. We also compare the larval morphology of these three species with the $M$. arion and $M$. rebeli.

The first to fourth larval instars will be referred to as LI to LIV, the larval thoracic segments as TI to TIII and the larval abdominal segments as AI to AIX (following Kitching \& Luke 1985; see Fig. 1a).

\section{Material and methods}

To present simple morphological features that can be used to distinguish the species and larval instars of juveniles of $M$. nausithous, $M$. teleius and $M$. alcon in geographically wide range of occurence, we used material from three locations in Central Europe and Asia. To describe the morphology of larvae feeding on the food plant (LI, LII, LIII and LIV), we gathered material in southern Poland, in Novosibirsk (Russia) and in Mongolia within 2002-2004. To distinguish species of $M$. teleius and M. nausithous, we used material from Mongolia, the region where, within Maculinea genus, only $M$. teleius were observed as the imago (M. Woyciechowski, unpubl. data). The description of caterpillars found on $S$. officinalis flowerheads in Mongolia presented the control for our observations in other regions. We had 190 caterpillars of $M$. teleius from this region conserved in ethanol (72\%). Finally, we identified live caterpillars of $M$. teleius found in flowerheads of $S$. officinalis: 270 larvae from southern Poland and 386 larvae from Novosibirsk region. For $M$. nausithous we described 691 alive caterpillars from southern Poland and 150 from Novosibirsk. To describe the morphology of M. alcon we used 10 alive larvae found in southern Poland within G. pneumonanthe flowers and 28 larvae conserved in ethanol $72 \%$ from Novosibirsk, found within flowers of G. macrophylla. Additionally, we obtained morphology of this species using scanning electron micrographs of LIII and LIV of M. alcon from Denmark that were compared with those from southern Poland and Novosibirsk. Because the examination of the larvae and pupae of $M$. rebeli revealed no diagnostic morphological features by which they can be distinguished from $M$. alcon, the description of $M$. alcon given here can apply equally well to $M$. rebeli. 

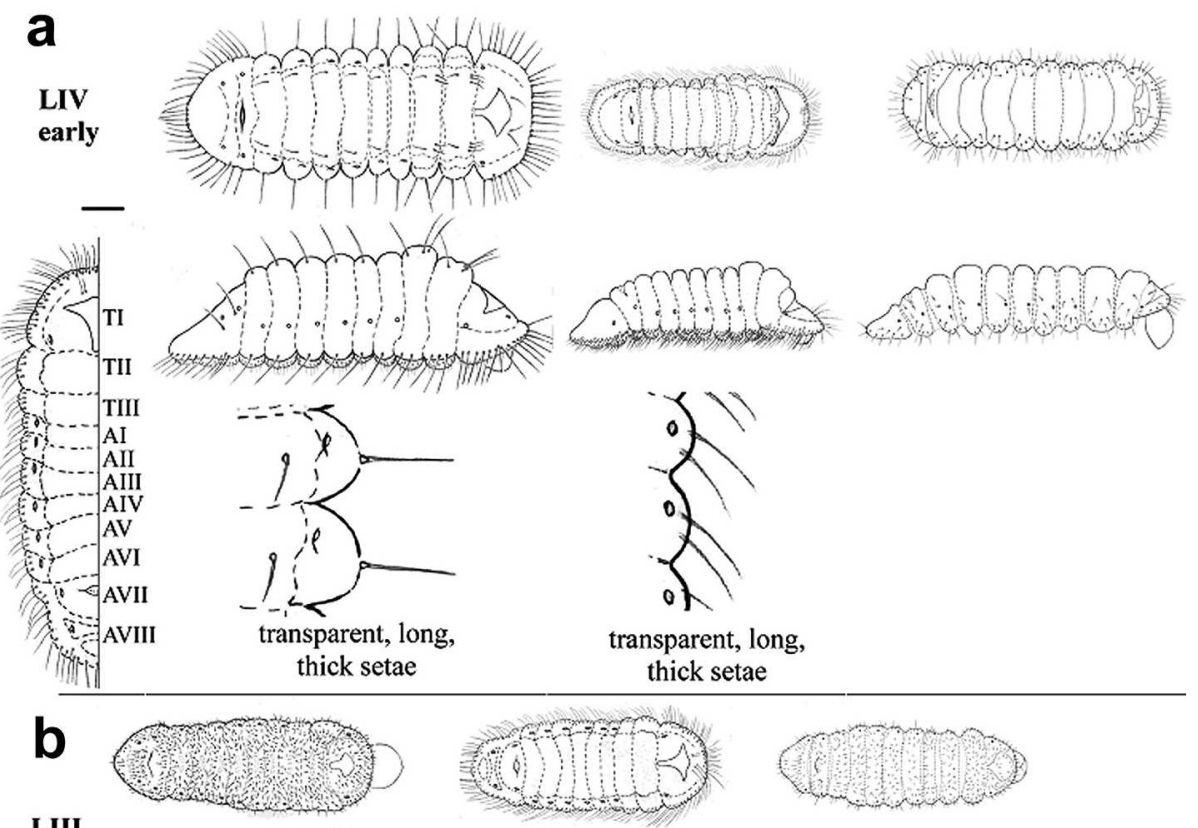

LIII
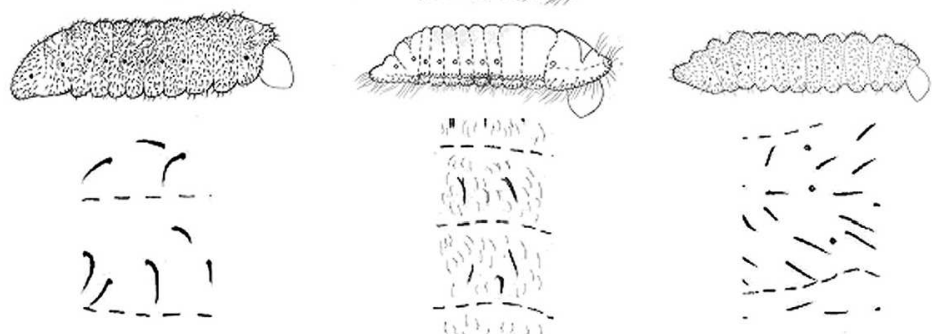

dark, short,

transparent, thin, short setae

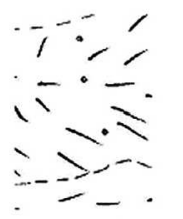

curved setae

M. nausithous

dark, short, straight setae

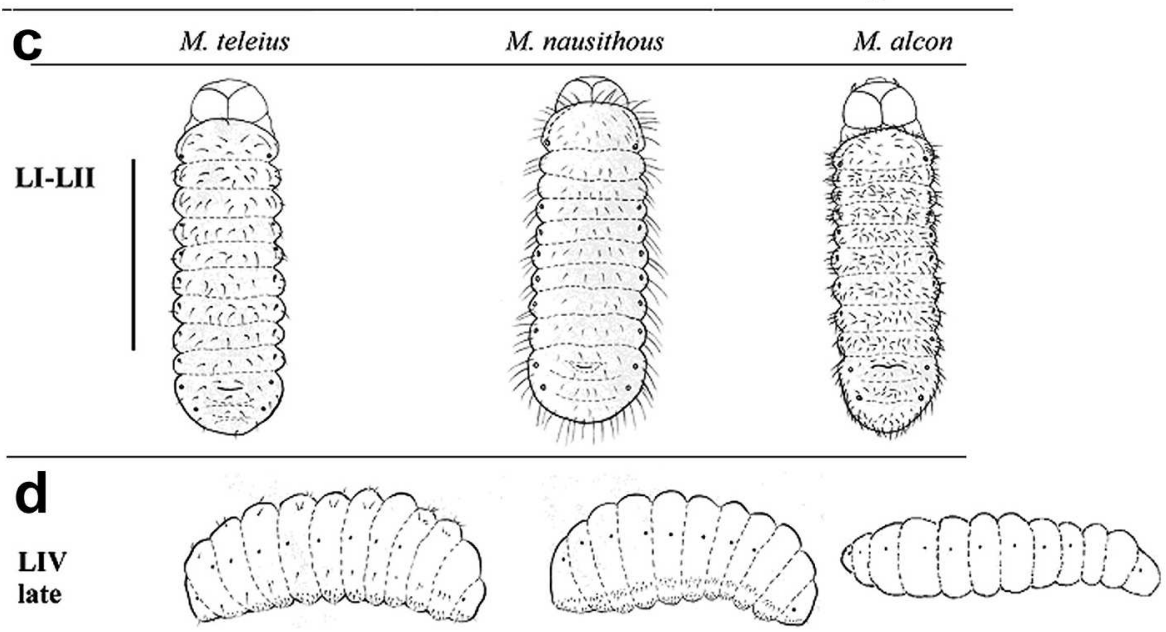

Fig. 1. - a. Dorsal and lateral views of the early fourth instar larvae, with insets showing the distribution and type of setae present on the cuticle, and the scheme used to label larval segments. b. Dorsal and lateral views of the third instar larvae, with insets showing the distribution and type of setae present on the cuticle. $-c$. Dorsal views of the first and second instar larvae of three Maculinea species. - d. Lateral views of the late fourth instar larvae, showing their characteristic shape. Scale bar $1 \mathrm{~mm}$. 


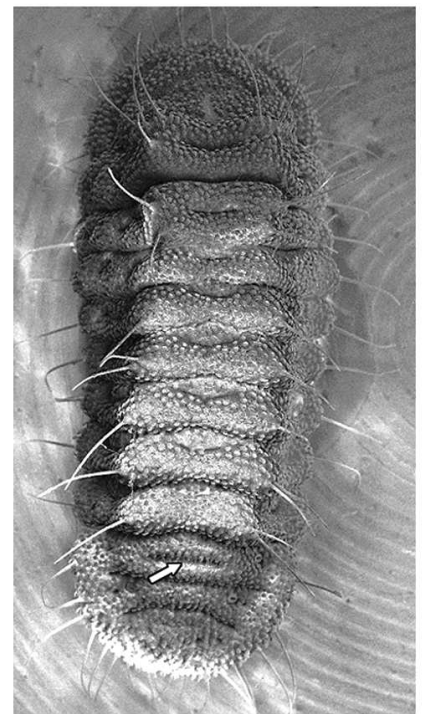

M. teleius

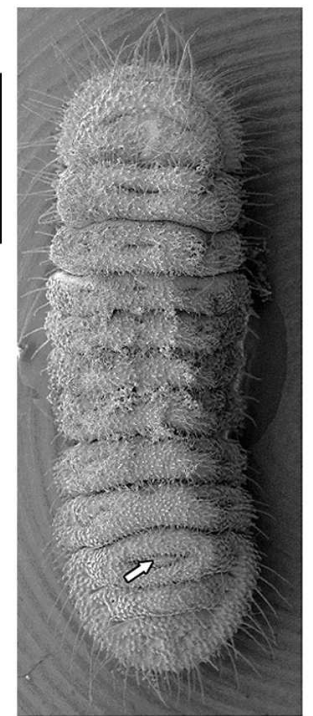

M. nausithous

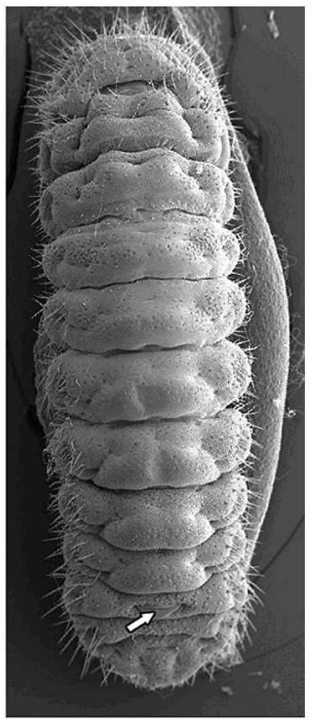

M. alcon
Fig. 2. Scanning electron micrographs of early fourth instar larvae of the three Maculinea species. The dorsal nectary organ is indicated with a white arrow. Scale bar $1 \mathrm{~mm}$.
To describe the larval (LIV) and pupal morphology within Myrmica ant nests, we used material gathered in Southern Poland. The nests were opened in the field and Maculinea caterpillars and pupae taken to laboratory. Next, we described the morphology and when individuals reached the imago stage we identified the Maculinea species. We gathered 58 larvae and 54 pupae for $M$. teleius, $M$. nausithous and $M$. alcon. We described morphology of 36 larvae and 41 pupae of $M$. teleius and 4 larvae and 2 pupae of $M$. nausithous. For M. alcon, we verified species and described morphology of 18 larvae from the ant nests and 11 pupae.

For observations and measurements we used Nikon microscope SMZ 1500 and Nikon digital camera CoolPix 995. In addition, scanning electron micrographs were used in the questionable cases of species and instar description.

\section{Caterpillar morphology}

\subsection{Ant-associated epidermal organs}

The ant-associated epidermal organs of the fourth instar larva of Maculinea arion have been described by Kitching \& Luke (1985). In short, there is a prominent Dorsal Nectary Organ
(DNO) on the seventh abdominal segment (AVII) of the caterpillar, and several Pore Cupola Organs (PCOs) scattered over the dorsal surface of the caterpillar.

This description also holds for fourth instar caterpillars of all other Maculinea species. The DNO produces droplets of a sugar-rich secretion, which is sometimes offered to Myrmica ants during the adoption of fourth instar caterpillars. The PCOs on the other hand are present on all larval instars, although they are found at the highest density on the fourth instar (Malicky 1969), and it is not clear whether their structure and function is the same for all instars.

\subsection{Setae and cuticle}

Four types of setae can be found on the cuticle of Maculinea caterpillars (Fig. 1a-b): (1) Transparent, short $(50-70 \mu \mathrm{m})$, thin setae. (2) Transparent, long $(100-700 \mu \mathrm{m})$, thick setae. (3) Dark, short $(50-120 \mu \mathrm{m})$, straight setae. (4) Dark, short (50$250 \mu \mathrm{m}$ ), slightly curved setae. The presence and distribution of these provides the best means to distinguish between the different Maculinea larvae. In addition, the general body shape and the presence or absence of enlarged segments and folds in the cuticle are useful cues. 
Fig. 3. Dorsal and lateral views of pupae of the three Maculinea species. There are no obvious morphological differences between the pupae of M. teleius and $M$. nausithous. Scale bar $1 \mathrm{~mm}$.
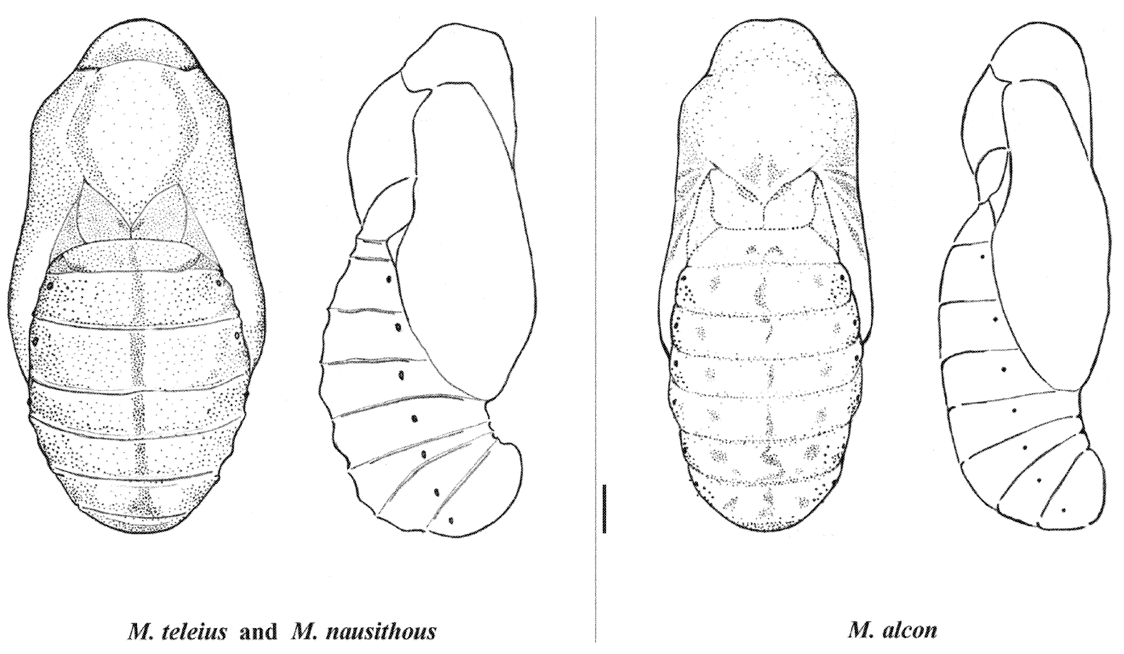

\subsection{Species description}

Below we give the characteristics of the larvae of the three sympatrically occurring Maculinea species.

\subsubsection{M. teleius}

LI and LII have setae distributed uniformly over the entire surface (Fig. 1c). They are placed irregularly, with the average distance between them similar to the length of a single seta $(50-100 \mu \mathrm{m})$. Setae are dark and slightly curved. LIII is generally similar, but the junction between the head and TI is covered by a small cuticular fold (Fig. $1 b)$.

In LIV the setae are transparent, thick and longer than those found on LIII (300-700 $\mu \mathrm{m})$. They grow sparsely but regularly on the dorsal surface of the thorax and abdomen, and in a fringe around the lateral margin of the caterpillar, with the average distance between setae on a recently moulted larva 200-300 $\mu \mathrm{m}$ (Fig. 1a). A cuticular fold of TI covers about $3 / 4$ of the head, and completely covers the junction between the head and the thorax. As the larval cuticle expands during growth in the ant nest, the density of setae becomes lower. The setae often break off during growth, but their darker-coloured bases remain visible, and the single pair of setae on the dorsal surface of AI to AVII is characteristic of $M$. teleius. The general body shape is initially onisciform (woodlouse- shaped; Fig 1a, Fig. 2), and becomes barrel-like just before pupation (Fig. 1d). The cuticle of this species is highly sculptured (Fig. 2) and appears dull and unreflective.

\subsubsection{M. nausithous}

LI and LII are covered with short $(50-70 \mu \mathrm{m})$, transparent setae growing densely on the dorsal surface of the body that are hardly visible, even at $100 \times$ magnification (Fig. 1c). There are also setae that are longer $(100-400 \mu \mathrm{m})$ in a fringe around the lateral margin and above the head. LIII is generally similar (Fig. 1b) although one or two long setae $(200-400 \mu \mathrm{m})$ are also sometimes found on the dorsal surface of TII.

LIV of $M$. nausithous generally resembles the previous instar, but with long setae $(100-400 \mu \mathrm{m})$ occurring in regular clusters along the lateral margins of the caterpillar (from seven to ten setae on TII and TIII, from four to five setae on AIAVIII; Fig. 1a). Caterpillars of M. nausithous in this stage are often much smaller than those of $M$. teleius. After growth in the ant nest, M. nausithous caterpillars can be recognised by the presence of several (from four to ten) dark setal bases on each abdominal and thoracic segment along the lateral side (Fig. 1d). The general body shape is again initially onisciform, but more rounded than M. teleius (Fig. 1a, Fig. 2), becoming barrelshaped just before pupation (Fig. 1d). The cuticle is again highly sculpted and unreflective (Fig. 2). 


\subsubsection{M. alcon}

LI-LII of $M$. alcon have dark, short (50-120 $\mu \mathrm{m})$ and straight setae covering the entire body at high density (the average distance between them is $30-40 \mu \mathrm{m})$ and distributed in no clear pattern (Fig. 1c). LIII differs from the earlier instars in the size and shape of segments: The thoracic segments (TI-TIII) are significantly longer and thinner than the abdominal segments, and have clear contractions between each segment (Fig. 1b).

LIV is characterised by transparent short setae $(50-120 \mu \mathrm{m})$ occurring across the surface of the body (Fig. 1a). The caterpillar in initially cylindrical in general shape, and remains this way until pupation, with clearly visible and distinct body segments (Fig. 1d). The cuticle of this species is particularly smooth and shiny (Fig. 2), and this becomes much more noticeable as the caterpillar develops in the ant nest.

\section{Pupal morphology}

The pupae of M. teleius and M. nausithous cannot readily be distinguished from each other. Both are stout, with a thick, dull cuticle (Fig. 3). The pupa of M. alcon is more slender, with a transparent, shiny cuticle (Fig. 3). The developing pupa of this species appears yellowish brown. Just before eclosion the wing pattern and colour becomes visible through the cuticle of pupae of described Maculinea species.

\section{Identification}

This section presents the identification of caterpillars living on foodplant, and shortly after adoption, and identification of large caterpillars and pupae found in ant nests. Note that LIII and even sometimes LII may emerge from their food plants under stressful conditions. The section ends with general notes on $M$. rebeli and $M$. arion.

\subsection{Larval surface}

i. Covered only with short $(50-250 \mu \mathrm{m})$, dark setae (Fig. 1b) a) Dark, straight setae, densely distributed, with average distances between them $30-40 \mu \mathrm{m}-$ M. alcon LI-LIII

- Thoracic segments thinner and longer than abdominal $-M$. alcon, LIII

b) Dark slightly curved setae, sparsely distributed, with average distances between them 50-100 $\mu \mathrm{m}-M$. teleius, LI-LIII

ii. Fringed by long $(100-400 \mu \mathrm{m})$ transparent setae above the legs and over the head (Fig. $1 \mathrm{a}-\mathrm{b})$

a) No enlarged segments $-M$. nausithous, LILIII

b) Segment TIII enlarged $-M$. nausithous, LIV

iii. Covered with long (300-700 $\mu \mathrm{m})$ transparent setae above the legs, over the head and on the dorsal part of the body (Fig. 1a)

a) Segments TIII and AVI enlarged-M. teleius, LIV

b) No enlarged segments $-M$. alcon, LIV

\subsection{Caterpillar}

i. Body barrel-like

- A single seta on the lateral side of each segment from AI to AVIII - M. teleius

- Several (from four to ten) setae on the lateral side of each segment $-M$. nausithous

ii. Body elongated, cylindrical $-M$. alcon

\subsection{Pupa}

i. Pupal cuticle - not transparent, thick, dark, dull-M. teleius, $M$. nausithous

ii. Pupal cuticle - transparent, thin, light-coloured, glossy - M. alcon

\section{4. $M$. rebeli and $M$. arion}

$M$. rebeli and $M$. arion generally occur in habitats and on food plants that are distinct from the other three European Maculinea species, so we have not included detailed morphological features here. The larvae and pupae of $M$. arion, on the other hand, are morphologically distinct from the other species. LI-LIII are covered by short, transparent setae at a medium density (distance be- 
tween setae is similar to their length), with LIII having some longer setae fringing the body. LIV has sparse, but regularly distributed long, thick, transparent setae, distributed as for M. teleius. The general body shape of $M$. arion LIV is also similar to that of $M$. teleius.

\section{Discussion}

The morphological differences between the different species of Maculinea, described here, may reflect different life history strategies employed. The most characteristic differences are in the fourth instar larva, which is the stage at which the majority of interactions between Maculinea butterflies and their Myrmica ant hosts take place. This instar has highly developed myrmecophilous organs, and many of the differences in morphology of this instar probably reflect variations in the myrmecophilous strategy employed by the different species (Malicky 1969, Kitching \& Luke 1985).

Maculinea butterflies develop in nests of Myrmica ants following one of two strategies. Predatory species (M. arion, $M$. teleius and $M$. nausithous) gain all their nutrition by feeding directly on the ant brood, and generally avoid contact with the worker ants in the nest as much as possible (Thomas \& Wardlaw 1992), while "cuckoo" species (M. alcon and $M$. rebeli) receive most of their nutrition in the form of food regurgitated by worker ants, and appear to show much tighter integration into the ant colony (Elmes et al. 1991). The differences in morphology between LIV for these two groups are striking. The predatory species have an onisciform body shape and possess long, stout setae both of which have been regarded as adaptations to avoid predation or damage to vital organs by worker ants (Malicky 1969). The cuckoo species, on the other hand, are cylindrical in shape and largely unprotected by setae. In addition, they possess a smooth, shiny cuticle, which probably reflects an abundance of cuticular hydrocarbons. These compounds are thought to be important for integration into the Myrmica colony through chemical mimicry of the ant brood (Akino et al. 1999, Elmes et al. 2002). It is interesting that in the morphological features of $M$. nausithous the typical characteristics of the other predatory species are less well expressed (e.g. sculpted cuticle) and a trend to more cuckoo species characteristics might be found, for example the body shape is more cylindrical than onisciform. While this species seems to be entirely predatory in its lifestyle, it might be much more tightly integrated into the host colony than other predatory species, possibly because it may have evolved to specialize in eating ant eggs (Elfferich 1998).

Acknowledgements. This study was financed by EC within its RTD project EVK2-CT-2001-00126.

\section{References}

Als, T. D., Nash, D. R. \& Boomsma, J. J. 2001: Adoption of parasitic Maculinea alcon caterpillars (Lepidoptera: Lycaenidae) by three Myrmica ant species. Animal Behaviour 62: 99-106.

Als, T. D., Vila, R., Kandul, N. P., Nash, D. R., Yen, S.-H., Hsu, Y.-F., Mignault, A. A., Boomsma, J. J. \& Pierce, N. E. 2004: The evolution of alternative parasitic life histories in Large Blue butterflies. - Nature 432: 386-390.

Akino, T., Knapp, J. J., Thomas, J. A. \& Elmes, G. W. 1999: Chemical mimicry and host specificity in the butterfly Maculinea rebeli, a social parasite of Myrmica ant colonies. - Proceedings of the Royal Society of London (B. Bio.) 266: 1419-1426.

Bereczki, J., Pecsenye, K., Peregovits, L. \& Varga Z. 2005: Pattern of genetic differentiation in the Maculinea alcon species group (Lepidoptera, Lycaenidae) in Central Europe. - Journal of Zoological System 43: 157-165.

Elfferich, N. 1998: New facts on the life history of the dusky large blue Maculinea nasithous (Lepidoptera: Lycaenidae) obtained by breeding with Myrmica ants in plaster nests. - Deinsea 4: 97-102.

Elmes, G. W. \& Thomas, J. A. 1992: Complexity of species conservation in managed habitats: interaction between Maculinea butterflies and their ant hosts. Biodiversity and Conservation 1: 155-169.

Elmes, G. W., Wardlaw, J. C. \& Thomas, J. A. 1991: Larvae of Maculinea rebeli, a large blue butterfly and their Myrmica host ants: patterns of caterpillar growth and survival. - Journal of Zoology 224: 79-92.

Elmes, G. W., Akino, T., Thomas, J., Clarke, R. T. \& Knapp, J. J. 2002: Interspecific differences in cuticular hydrocarbon profiles of Myrmica ants are sufficiently consistent to explain host specificity by Maculinea (large blue) butterflies. - Oecologia 130: 525-535.

Elmes, G. W., Thomas, J. A., Hammarstedt, O., Munguira, M. L., Martin, J. \& Van Der Made, J. G. 1994: Differences in host-ant specificity between Spanish, Dutch and Swedish populations of the endangered butterfly, 
Maculinea alcon (Denis and Schiff.) (Lepidoptera). - Memorabilia Zoologica 48: 55-68.

Figurny, E. \& Tomaszewicz, S. 1997: Pasożytnictwo gąsienic motyli Maculinea teleius (Lepidoptera: Lycaenidae) i $M$. nausithous w gniazdach mrówek Myrmica scabrinodis i $M$. rubra. - In: Współczesne kierunki ekologii, Ekologia behawioralna, Symphosium materials, Maria Curie - Skłodowska University, Lublin, Poland. [In Polish.]

Figurny, E. \& Woyciechowski, M. 1998: Flowerhead selection for oviposition by females of the sympatric butterfly species Maculinea teleius and M. nausithous (Lepidoptera, Lycaenidae). - Entomologia Generalis 23: 215-222.

Jutzeler, D. 1988: Verbreitung von Maculinea alcon (Denis \& Schiffermuller, 1775) im Grossraum Zürichsee (Lep., Lycaenidae). - Mitteilungen Entomologische Gesellschaft Basel 38: 126-133.

Kitching, R. L. 1983: Myrmecophilous organs of the larvae and pupae of the lycaenid butterfly, Jalmenus evagoras (Donovan). - Journal of Natural History 17: 471-81.

Kitching, R. L \& Luke, B. 1985: The myrmecophilous organs of the larvae of some British Lycaenidae (Lepidoptera): a comparative study, - Journal of Natural History 19: 259-276.

Malicky, H. 1969: Versuch einer Analyse der ökologischen Beziehungen zwischen Lycaeniden (Lepidoptera) und Formiciden (Hymenoptera). Tijdschrift voor Entomologie 112: 213-298.

Munguira, M.L. 1989: Biología u Biogeografia de los licenidos ibericos en peligro de extinción (Lepidoptera: Lycaenidae). - Servicio Publicaciones Univ.
Autonoma de Madrid, Madrid. [In spanish.]

Munguira, M. L. \& Martin, J. 1993: The conservation of endangered lycaenid butterflies in Spain. - Biological Conservation 66: 17-22.

Sielezniew, M. \& Stankiewicz, A. 2001: First data on hostant specificity of parasitic Maculinea alcon (Den. \& Schiff.) (Lepidoptera: Lycaenidae) in Poland and eastern Europe. - Fragmenta Faunistica 45: 123-130.

Stankiewicz, A. \& Sielezniew, M. 2002: Host specificity of Maculinea teleius Bgstr. and M. nausithous Bgstr. (Lepidoptera: Lycaenidae): the new insight. — Annales Zoologici 52: 403-408.

Thomas, J. A. 1984: The behaviour and habitat requirements of Maculinea nausithous (the Dusky Large Blue butterfly) and $M$. teleius (the Scarce Large Blue) in France. - Biological Conservation 28: 325-347.

Thomas, J. A. \& Wardlaw, J. C. 1992: The capacity of a Myrmica ant nest to support a predacious species of Maculinea butterfly. - Oecologia 91: 101-109.

Thomas, J. A., Elmes, G. W., Wardlaw, J. C. \& Woyciechowski, M. 1989: Host specificity among Maculinea butterflies in Myrmica ant nests. - Oecologia 79: 452- 457.

Wells, S. M., Pyle, R. M. \& Collins, N. M. 1983: The IUCN Red Data Book: Invertebrates. - Gland, Switzerland, IUCN.

Wynhoff, I. 1998: The recent distribution of the European Maculinea species. - Journal of Insect Conservation 2: 15-29.

Wynhoff, I. 2001: At home on foreign meadows. The reintroduction of two Maculinea butterfly species. - $\mathrm{PhD}$ thesis, Department of Environmental Sciences, Wageningen University, The Netherlands. 